RESEARCH ARTICLE

\title{
Evaluating Factors Contributing to Positive Partnership Work in a Students-as-Consultants Partnership Program
}

\author{
*Gabrielle Foran, McMaster University, Hamilton, Ontario, Canada \\ Kris Knorr, Paul R. MacPherson Institute, McMaster University, Hamilton, Ontario, Canada \\ Rebecca L Taylor, Paul R. MacPherson Institute, McMaster University, Hamilton, Ontario, \\ Canada
}

Contact: gyforan@gmail.com

\begin{abstract}
McMaster University pioneered its Course Design/Delivery Consultants Program (CDDCP) in fall 2016. This program pairs an instructor partner who is teaching or preparing to teach a course with a student partner to obtain a student's perspective on teaching and learning in their classroom. Although the CDDCP was based on Healey, Flint, and Harrington's (2014) eight values of partnership, the contribution of other factors to its success was of interest. Participants' experiences were analyzed using a framework informed by these values. Qualitative analysis showed that these values were reflected in participants' experiences. Additionally, it was revealed that participants' experiences in the CDDCP were enhanced by two additional factors: (a) prior experiences and experiences gained through CDDCP participation and (b) the extensive program structure of the CDDCP. These findings suggest that partnership programs involving students, instructors, and coordinators should (a) explicitly acknowledge the value of participants' experiences and (b) facilitate face-to-face time among participants.
\end{abstract}

\section{KEYWORDS}

students as partners, course design, experience, program structure, course delivery

The Students-as-Partners (SaP) movement for the improvement of teaching and learning at the post-secondary level has grown considerably over the past decade (Cook-Sather, 2010). Since being formally established in North America in 2007 (Cook-Sather, 2014), institutions in the United States and Canada, including McMaster University (Goff \& Knorr, 2018; Marquis et al., 2016), have created opportunities for students and instructors to work in 
partnership to accomplish shared teaching and learning goals. This type of collaborative work empowers students by positioning them as experts on the student experience while instructors remain disciplinary experts (Cook-Sather, 2014).

To capture similarities across numerous unique partnership contexts, Healey, Flint, and Harrington (2014) identified a set of eight partnership values (see Table 1) to guide effective SaP practice such that mutual exchange of ideas between partners is encouraged regardless of their roles in the traditional university hierarchy. These values, as well as subsequent literature on SaP practices (e.g., Matthews, 2017), enforce the notion that while existing power structures cannot be completely eradicated, power can be re-distributed among partners. Power can also be differently distributed when not only students and instructors, but also educational developers (also referred to as academic or faculty developers) collaborate on curriculum design projects (Goff \& Knorr, 2018). Educational developers bring expertise in pedagogy and collaboration with both students and instructors. In a partnership context, these skills can be leveraged to connect student and instructor partners and assist in the establishment of a genuine partnership relationship (Healey, Flint, \& Harrington, 2016; Goff \& Knorr, 2018).

Table 1. Eight underpinning values of partnership practice (Healey et al., 2014)

$$
\text { VALUES OF PARTNERSHIP }
$$

\begin{tabular}{cccc}
\hline Authenticity & Community & Inclusivity & Challenge \\
Trust & Responsibility & Reciprocity & Empowerment \\
\hline
\end{tabular}

The relationship among partners is critical yet can be challenging to establish for multiple reasons. First, for each member to make meaningful contributions, a transition from the traditional hierarchical relationships between students and instructors must occur (CookSather, 2014; Marquis et al., 2016; Ntem \& Cook-Sather, 2018). This requires that students and instructors cross over a threshold wherein they let go of their initial resistances and pre-existing assumptions to accept their partner as a person and a holder and creator of equally valid knowledge (Marquis et al., 2016; Ntem \& Cook-Sather, 2018). Once partners have gotten to know each other in this context, preconceptions are transcended and true SaP work can begin (Ntem \& Cook-Sather, 2018). Instructor partners in Flint and Millard's (2018) study suggest that sharing time through collaborative projects and informal social settings is integral to building relationships. Furthermore, these instructors cite some of Healey et al.'s (2014) eight values for partnership-community, inclusivity, authenticity, trust, and responsibility-as being integral to establishing partnership relationships with students. Previously unexplored is whether these values also hold an integral place in the development of partnerships between students, instructors, and program coordinators. 
Another common challenge to partnership is that students and instructors do not often organically come together to collaborate on post-secondary teaching and learning projects. This may be a result of the private nature of post-secondary teaching, as curricula are typically developed by instructors in the absence of formal evaluation or instruction (Cook-Sather, 2014). It therefore may be uncomfortable for individuals to invite another person into their practice, particularly for the purpose of dialogue surrounding changes to that practice. One way in which this can be accomplished is having experienced partners model the student-instructor partnership approach. Work presented by Clancy, Ferreira, and Thompson (2019) demonstrates that having course coordinators who model student-instructor partnerships can encourage this behavior amongst participants in SaP programs. As this work was framed by some of Healey et al.'s (2014) values for partnership - trust, reciprocity, authenticity, and community-it is of interest whether these values contribute to the development of student-instructor partnerships or if additional factors are involved.

\section{The Course Design/Delivery Consultants Program at McMaster University}

Launched at McMaster University in Hamilton, Ontario in 2016, the Course Design/Delivery Consultants Program (CDDCP) is a semester-long partnership program which brings students, instructors, and educational developers together to enhance courses taught at the university. Facilitated by a team of coordinators comprised of two educational developers and one experienced student partner, students and instructors work collaboratively on a course's design or delivery with the intention of incorporating the student partner's expertise in post-secondary teaching and learning. The design stream pairs a student with an instructor who will teach a course in an upcoming semester. The student partner's role is to co-develop aspects of the course that the instructor partner would like to be enhanced by a student's perspective. In the delivery stream, a student is paired with an instructor who is currently teaching a course. The student partner's role is to provide feedback on the teaching and learning that occurs in the classroom and make suggestions based on the feedback to the instructor partner.

In the CDDCP, students and instructors are guided through the program by the coordinators, who introduce partners to Healey et al.'s (2014) underpinning values of partnership (Table 1) during an orientation session taking place early in the semester and who model the values in their own interactions throughout. During the orientation session, the coordinator team offers participants administrative and training support which are delivered over regularly scheduled meetings (see Table 2). These meetings typically involve a combination of instruction on pedagogical topics, facilitated discussion between partners, and reminders of program logistics and deadlines. In addition to the meetings, coordinators communicate the expectation that student and instructor partners meet on a weekly basis. At the conclusion of each semester, student and instructor partners are asked to co-author and submit a project reflection that describes (a) their experiences in partnership, (b) project accomplishments, and (c) any challenges faced throughout their partnership (see Appendix I: CDDCP End-of-Semester Reflection Questions). 
Table 2. Sample semester schedule for McMaster University's CDDCP

\begin{tabular}{|c|c|c|}
\hline $\begin{array}{l}\text { SEMESTER } \\
\text { WEEK }\end{array}$ & ACTIVITY & PARTICIPANTS \\
\hline 1 & Orientation session & $\begin{array}{l}\text { Coordinators, students, } \\
\text { instructors }\end{array}$ \\
\hline 2 & Fundamentals of Pedagogy session & Coordinators, students \\
\hline 3 & No meeting & N/A \\
\hline 4 & Course outlines/structure & Coordinators, students \\
\hline 5 & Student-instructor check-in session 1 & $\begin{array}{l}\text { Coordinators, students, } \\
\text { instructors }\end{array}$ \\
\hline 6 & Students choose meeting topic & Coordinators, students \\
\hline 7 & No meeting (midterm break) & N/A \\
\hline 8 & $\begin{array}{l}\text { Student/instructor project updates } \\
\text { (separate meetings) }\end{array}$ & $\begin{array}{l}\text { Coordinators, students } \\
\text { Coordinators, instructors }\end{array}$ \\
\hline 9 & Off & N/A \\
\hline 10 & Student-instructor check-in session 2 & $\begin{array}{l}\text { Coordinators, atudents, } \\
\text { instructors }\end{array}$ \\
\hline 11 & Students choose meeting topic & Coordinators, students \\
\hline 12 & Off & N/A \\
\hline 13 & Closure session & Coordinators, students \\
\hline
\end{tabular}

Following the orientation session, student partners are required to attend a Fundamentals of Pedagogy half-day session facilitated by the coordinators (Table 2). This session is designed to introduce students to fundamental theory and techniques in course Foran, G., Knorr, K. \& Taylor, R. L. (2020). Evaluating factors contributing to positive partnership 
design or delivery, including constructive alignment, formative and summative assessment, learning outcomes, active learning techniques, and universal design for learning. Additional coordinator-facilitated sessions on pedagogical topics are offered in one-hour biweekly meetings throughout the semester, including developing course structure and course outlines and "student choice" sessions for which student partners are asked to recommend topics that would be useful to their project work (Table 2).

Beyond instructing partners, the coordinators also facilitate three sessions focused on project progress updates. Two student-instructor check-in sessions, which are held in weeks 4 and 10 , are one-on-one meetings between a student-instructor team and the coordinators (Table 2). These 30-minute meetings give partnership teams the opportunity to reflect on their progress, discuss challenges specific to their project, and receive feedback from the coordinators. To provide a complementary opportunity for partnership teams to learn and obtain feedback from one another, project update sessions, scheduled in week 8 (separate meetings for student and instructor partners) provide the opportunity for partners to present and ask for input on their course design or delivery projects to their peers (Table 2). The CDDCP ends with a closure session (Table 2) providing student partners with the opportunity to anonymously share their feedback on the CDDCP with the coordinator team. All program activities (Table 2 ) are attended by both design and delivery stream partners.

The CDDCP has been continuously subjected to a series of iterative changes between each semester by the coordinators. These changes have been motivated by the experiences and end-of-semester feedback of previous student, instructor, and coordinator participants. The overall result of this approach to program improvement is that aspects of the program that are not working well are resolved quickly; however, during the years of 2016-2018 a more robust program evaluation of the CDDCP had not occurred. To conduct a more formal review of the program, the authors felt that a review based on the partnership values as described by Healey et al. (2014) was necessary to (a) determine whether participants' experiences within the CDDCP are well-aligned with these values and (b) identify any additional factors that contribute to positive partnership work in the CDDCP such that these can be highlighted and promoted in future offerings. This latter goal was of interest because the CDDCP includes coordinator participants, whereas the values articulated in Healey et al. (2014) focus solely on student-instructor relationships. As we wanted to determine whether additional values are important to the promotion of positive partnership work in the program, it was determined that a large-scale analysis of multiple cohorts of program participants would be more effective than iteratively evaluating each cohort individually. To these ends, several cohorts of student partners', instructor partners', and coordinators' experiences and feedback were investigated.

\section{METHODS}

This study used two qualitative methods to approach its questions. First, data were gathered from students $(n=36)$ and instructors $(n=31)$ who participated in the CDDCP between September 2016 and April 2018. As mentioned above, end-of-semester reflections completed by student and instructor partners constituted our student and instructor data. Following institutional research ethics approval, these end-of-semester reflections were 
anonymized and used as secondary data. The reflections included questions soliciting partners' observations on partnership goals, accomplished tasks, experiences of working in partnership, and the usefulness of various aspects of the CDDCP's structure (Appendix I: CDDCP End-ofSemester Reflection Questions).

Second, CDDCP coordinators ( $n=3$ ) who delivered the CDDCP between September 2016 and April 2018 (the authors) participated in a collaborative autoethnographical focus group, a method used to investigate group experiences and perceptions that is often used in highereducation academic development contexts (e.g., Chang, Longman, \& Franco, 2014; MercerMapstone et al., 2017). The focus group format, rather than individual interviews, was used so that richer discussion on various aspects of coordinating the CDDCP could be generated. Questions for this focus group (Appendix II) solicited coordinators' reflections on topics such as coordinator roles, program highlights and challenges, and possible future changes to the program. The focus group discussion was audio-recorded and transcribed.

To examine the program's continued alignment with the eight values underpinning partnership practice (Healey et al., 2014; Table 1), these values were used as a conceptual framework to guide our qualitative analysis. Additionally, we were open to exploring other factors that may have contributed significantly to the participants' experiences in the program.

Anonymized data from student and instructor partners were organized based on the semester in which they participated in the CDDCP and aggregated for analysis. Data from the coordinator focus group, which included coordinator feedback on all semesters, was anonymized and analyzed using the same set of codes, which allowed for easy comparison to data collected from the student and instructor partners.

Data sets were coded using Atlas.ti (version 19) software. An open coding process was used to analyze end-of semester reflections and focus group transcripts using the codes indicated above (Creswell, 2012). In some cases, and as necessary, paragraphs or phrases may have been tagged with more than one code. A total of 310 sentences or phrases were coded using the eight values described by Healey et al. (2014).

\section{RESULTS AND DISCUSSION}

Our open-coding analysis revealed that Healey et al.'s (2014) eight values, as well as two additional factors - participant experience and program structure-are prevalent in the data. Specifically, the majority of the sentences/phrases were coded with the eight values, with a cumulative frequency of $58.4 \%$ for all eight codes; however, more greatly weighted in the data than each of the individual eight value-based codes were the codes of experience and structure, with a frequency of $11.0 \%$ and $11.3 \%$, respectively. Table 3 illustrates the codes used in the study and quotations from student, instructor, and coordinator participants that evidence their relevance.

Table 3. Sample quotations from participant feedback and their relevance to the CDDCP

$$
\text { CODE }
$$

CDDCP RELEVANCE

SUPPORTING QUOTATION

Foran, G., Knorr, K. \& Taylor, R. L. (2020). Evaluating factors contributing to positive partnership 


\begin{tabular}{|c|c|c|}
\hline Authenticity & $\begin{array}{l}\text { Working with a student partner } \\
\text { encourages incorporating authentic } \\
\text { student voices into course design. }\end{array}$ & $\begin{array}{l}\text { Instructor: "I believe students' } \\
\text { input regarding course design is } \\
\text { very important, students often } \\
\text { perceive aspects of the course } \\
\text { differently from instructors." }\end{array}$ \\
\hline Challenge & $\begin{array}{l}\text { One of the most significant } \\
\text { challenges for partners is keeping } \\
\text { track of program requirements. }\end{array}$ & $\begin{array}{l}\text { Student: "A large challenge } \\
\text { working in this partnership has } \\
\text { been finding the time to } \\
\text { physically 'do it'." }\end{array}$ \\
\hline Community & $\begin{array}{l}\text { Program coordinators organize } \\
\text { events for students and instructors } \\
\text { to build community amongst (and } \\
\text { between) these groups. }\end{array}$ & $\begin{array}{l}\text { Coordinator: "The student } \\
\text { [partner]s suggested to try } \\
\text { more student updates. . . it } \\
\text { sounds like they really just } \\
\text { want to have a chance to hear } \\
\text { what's happening and talk } \\
\text { about common issues or try } \\
\text { and solve problems for one } \\
\text { another." }\end{array}$ \\
\hline
\end{tabular}

Empowerment Partners tend to feel empowered when they can use their experiences to make valuable contributions to their partnership.

Student: "I had a great amount of influence on the way the tutorial projects were developed and run. . I I used my own experiences in tutorial projects to ensure that students would be motivated and interested."

Student: "I had taken the course and right off the bat we were on the same page." 


$\begin{array}{lll}\text { Reciprocity } & \begin{array}{l}\text { Each iteration of the CDDCP is the } \\ \text { result of dialogue between } \\ \text { students, instructors, and } \\ \text { coordinators. }\end{array} & \begin{array}{l}\text { Coordinator: "One thing that is } \\ \text { very effective is the iterative } \\ \text { process that this program } \\ \text { takes: things that are not } \\ \text { working well are addressed } \\ \text { very rapidly." }\end{array} \\ \text { Responsibility } & \begin{array}{l}\text { Sharing course design/delivery } \\ \text { responsibilities with a partner helps } \\ \text { students and instructors stay on } \\ \text { track. }\end{array} & \begin{array}{l}\text { Instructor: "Having a student } \\ \text { partner made me stay on track } \\ \text { and set reasonable goals and } \\ \text { deadlines for myself." }\end{array}\end{array}$

Trust $\quad$ Partners establish trust more quickly when they know that each has disciplinary knowledge to draw upon.
Coordinator: "Both students and faculty members were more comfortable working together knowing that their partner had the same background. It can be helpful to have people speaking the same language from the beginning."

Student: "My previous experiences as an engaged student and teaching assistant contributed to building rapport with my faculty partner."
Participant Experience
Prior experience in their discipline provides students with a foundation upon which to begin their partnerships. with my faculty partner." 
Program Program structure aides bringing Structure partners together.

\author{
Instructor: "The partnership \\ check-in sessions were very \\ helpful in ensuring open \\ communication between the \\ student and the faculty \\ member. These meetings \\ encouraged giving and \\ receiving feedback in a \\ productive manner and helped \\ keep us focused on our tasks."
}

The presence of Healey et al.'s (2014) eight values in our data derived from the end-ofsemester reflections from the student and instructor partners is reassuring as the CDDCP was designed with these eight values in mind and these values are shared with student and instructor partners at the outset of their projects. This satisfies this study's first goal by confirming that participants' CDDCP experiences continue to reflect the values upon which the program was based. This finding is significant to the authors as it indicates that their communication and modelling of Healey et al.'s (2014) eight values as coordinators has been successful. Largely, our novel insights from the data are twofold. First, prior experiences and CDDCP experiences provided participants with tools and skills to build effective partnership relationships, engage in dialogue surrounding course design and course delivery, and achieve project outcomes. Second, the structure of the CDDCP is integral to the success of the program. These findings speak to the second goal of our study to identify additional factors that significantly contribute to the practice of working positively in partnership in the CDDCP. For the remainder of this paper, we focus our attention on the newly identified factors of experience and structure and relate these to the experiences and perceptions of student partners, instructor partners, and educational developer coordinators of the CDDCP program.

\section{Participant Experience}

In our data, the notion of "participant experience" encompasses a variety of different contexts including experiences held prior to partners' involvement in the program and experiences that are gained by partners through the CDDCP. Marquis, Jayaratnam, Mishra, and Rybkina (2018) assert that student partners' prior academic or extracurricular experience can significantly impact their decision to participate in student-faculty partnership and their confidence when developing a partnership relationship. In this work, we seek to expand upon these findings by exploring the contributions of previous and program-gained experience towards the creation of student-instructor partnerships for students, instructors, and coordinators.

The experiences reported by all CDDCP participants indicated that there is significant value for student and instructor partners to share disciplinary expertise. Several instructor partners indicated a preference for a student partner with previous disciplinary experience or who had previously taken the course being designed/delivered. In the words of one instructor 
partner, their course-delivery student partner's prior disciplinary experience was beneficial for both themselves and the students currently enrolled in the course: "the partnership worked particularly well as my student partner had previously taken the mentoring course and was able to provide suggestions and advice to me and the students taking the course." This sentiment was corroborated by coordinators, who noted in the focus group that projects involving partners with different disciplinary backgrounds required more time for partners to establish trust. This challenge, faced by the coordinator team in the first two iterations of the CDDCP, resulted in students and instructors being less confident in taking on partnership work, prompting a switch towards pairing partners from similar academic disciplines in subsequent terms.

Interestingly, when describing a SaP partnership program at Bryn Mawr College, CookSather (2016) reported that it was beneficial when student and instructor partners were in different disciplines. Our findings report a contrasting view in part because a student's knowledge of disciplinary basics can act as a bridge in the development of a partnership relationship and in part because the lived student experience becomes directly relevant in partnerships where the student has previously taken their instructor partner's course. CDDCP student partners reported feeling empowered by their previous experiences in their partners' courses. For example, one student partner noted:

Through working in the partnership, I influenced the process of course design by incorporating learning resources. . . [and] reorganized, and structured the course in a way that I thought was beneficial for the student's learning experience based on my own experience of taking the course.

This student's perspective is echoed by Martens, Sprujit, Wolfhagen, Whittingham, and Dolmans' (2019) research findings that prior knowledge of an instructor partner's course results in increased confidence and success for student partners.

In addition to articulating the value brought by students with prior disciplinary experience, our findings suggest that student perspectives are also a valuable type of prior experience. For example, one instructor explained that student partners can act as representatives for their peers when evaluating course delivery:

It's important to have direct and thorough feedback from someone very close to students - to gauge various aspects of the course, from choosing adequate themes for, and design of activities, to assessment, to knowing how students react to the material presented in class, to knowing what students actually do during lectures.

This perspective, found throughout student, instructor, and coordinator data, reinforces previously reported findings of the value of incorporating the student voice in other SaP 
programs and in post-secondary teaching and learning in general (Cook-Sather, 2014; Jensen \& Bagnall, 2015; Matthews, 2017).

Instructors similarly enter partnerships with valuable prior experiences. Instructor partners indicated their prior disciplinary experiences and experiences in postsecondary teaching were assets to their partnerships. These experiences can help form relationships between partners, inform course design and delivery decisions made collectively by the student and the instructor, and bring an awareness of external limitations that students may not have such as time, funding, and program-level constraints. Coordinators also noted that instructors' prior experience with the scholarship of teaching and learning (SoTL) or scholarly teaching helps with instructors' initial willingness to engage in partnership work with students, which can feel like a vulnerable act (Cook-Sather, 2015).

The CDDCP coordinators - two educational developers and one graduate student-are also informed by previous experiences. The most valuable prior experience identified by the educational developer coordinators is their years of experience working with both students and instructors, with one explaining, "the greatest experience that I bring to this is the prior experience of my roles in partnerships, and trying to then foster that among people who are new to partnership." The student coordinator drew on their experiences of being a student and working with faculty in a research capacity. Additionally, previous project management and organizational experience was noted as necessary for the success of the CDDCP because of the large amount of administrative and coordination work that the program entails.

In addition to prior experience, it was noted that student and instructor partners gain useful experience during their participation in the CDDCP such that it develops partners' pedagogical knowledge, insight, and understanding of post-secondary education processes and aims. An example of the program directly shaping pedagogical knowledge is the half-day Fundamentals of Pedagogy session (Table 2), which was highlighted by student partners for its benefit. As explained by one student: "The first information meeting teaching the student partners the basics of course design, how to begin by shaping course objectives, and how to approach the design of assessments and course content was the most helpful." Even though instructor partners were not present at the student sessions, they noted that they benefited through their student partner's participation. In the words of an instructor partner, "the student sessions were very useful since they allowed the student partners an opportunity to bring back information relevant to their project back to the instructor partner."

Speaking to new insights in instructors and student partners, one student partner shared:

My perspective on teaching and learning has changed. Prior to the start of this project, I saw the development of a new course or program to be the exclusive responsibility of instructors/professors/administrators with experience or expertise in the topic of that course. Now, having assisted my faculty partner in the development of a new engineering program, it is clear to me that regardless of one's background, one can always bring valuable ideas to a project. 
Similarly, instructor partners indicated heightened appreciation of how useful the perspective of a learner can be. In the words of one instructor, "we believe working in partnership definitely enhanced the process of course design. My student partner and I worked very well together and were able to problem solve efficiently and effectively to make our planning sessions extremely productive." These perspectives offer some insight on the transformative power of partnership.

In contrast to student and instructor partners, coordinator participants tended to view their CDDCP experiences as iterative as opposed to transformative. This iterative view is attributed to two reasons. First, most of what the coordinators learned while running the CDDCP regarding students, instructors, and partnership was applied promptly to improve the CDDCP for all participants. Second, the CDDCP coordinator role is similar to the work that educational developers, and to some extent graduate students, do with students and instructors in other teaching and research capacities.

\section{Program Structure}

Program structure was identified as the other important factor of the CDDCP's design through the qualitative analysis of participant feedback. Its importance was complex in nature in that the structure posed both a benefit and challenge to participants. Comments from all three groups indicated that the program structure tends to be a source of difficulty, yet a driver of increased accountability in partners.

The CDDCP structure entails a high frequency of program meetings between student partners and coordinators. As demonstrated in Table 2, the coordinators schedule events involving the student and/or instructor partners most weeks of the semester. This distinguishes the CDDCP from common types of SaP programs (e.g., Healey et al., 2016; Jensen \& Bagnall, 2015) due to its relatively rigorous structure, but is at about par with some SaP projects which follow a similar framework (e.g., Cook-Sather, 2010; Oleson \& Hovakimyan, 2017). Requiring a significant time commitment for participation in SaP programs is identified as a limiting factor for prospective student participants (Marquis et al., 2018). In our data, while the coordinators noted multiple benefits of having regular pedagogical learning experiences for student partners as discussed above, they also acknowledged the challenge involved in scheduling and facilitating these events due to scheduling conflicts and time required to facilitate the program.

Another challenge associated with the high frequency of CDDCP meetings is that it limits the number of students that can participate in each offering of the program. From the coordinators' perspective, scheduling meetings becomes more difficult when more people are involved. Two solutions have been proposed to overcome this challenge. One, which was attempted during our second semester running the CDDCP and did not work well, was holding two versions of the same meeting every week. This permitted more students to attend but limited student-student collaboration and involved a significant amount of coordinator time. The second solution, which was used successfully in a more recent iteration, alternated meetings between the two most popular timeslots. This strategy prevented some students from attending all meetings, but the alternating of meeting times allowed coordinators to 
interact with all student partners at least some of the time, while still making more efficient use of coordinator time. To compensate for the drawback with this solution, coordinators offered to catch students up as needed.

Despite the challenges associated with a rigorous program structure, the CDDCP structure is intentionally rigorous due to benefits noted by the coordinators. In particular, instructor participation has been positively impacted by program structure, as observed through the context of iterative program changes between semesters. When the CDDCP was first established, program meetings were targeted solely towards the student partners, which resulted in a lack of instructor partner engagement. This led coordinators to introduce meetings where instructor presence was required as of the fall 2017 semester: an orientation meeting, two partnership check-in sessions, and an instructor-only mid-semester meeting (Table 2). Coordinators have since observed increased engagement in the CDDCP amongst instructor partners. Additionally, student partners have reported increased willingness amongst instructor partners to engage in positive partnership work.

This suggests that the various program meeting requirements and associated social pressure on instructors to discuss their partnership work with the coordinators has led to increased accountability and motivation to work collaboratively with their student partner. Furthermore, instructor partners appear to be appreciative of scheduled opportunities to connect (Table 2) as they found it effective in keeping them engaged with their student partners and the demands of the CDDCP. To this end, one instructor stated: "I was glad to attend these [check-in sessions]. During these meetings, I could ask questions and ensure that we were meeting not only our objectives but also the expectations with respect to the CDDCP outcomes." In addition to regular program meetings with coordinators, strong recommendations are made to student and instructor partners at the outset of their project to schedule weekly project meetings together (without coordinator presence) to encourage completion of tasks relating to partnership. The concomitant benefit and challenge of this additional program structure is best demonstrated by comparing the experiences of partners who enacted this recommendation to different degrees. For example, one student partner who participated in an early iteration of the CDDCP where the necessity of regular meetings between student and instructor partners was not as heavily encouraged by the coordinators outlined their challenges associated with scheduling despite a clear desire to take on an active role in the partnership:

I was unable to attend class or meet with my faculty partner every week due to scheduling issues, so it was hard to keep up with everything that went on during the course. If I could do it again, I would try to meet my faculty partner at least once per week, so I can be more active in course planning.

Meanwhile, students who experienced similar challenges but participated in later iterations of the CDDCP with more structural supports including weekly meetings and 
scheduled check-in sessions with the coordinators were more likely to be able to overcome the challenges of busy academic life:

Due to busy academic and work schedules, and the number of hours allotted during the term, planning sessions were often limited to one hour per week. While this time was well used, there were instances where we were building strong momentum and achieving great results but would have to end the session due to time restraints or other commitments. To overcome these challenges, we would assign tasks to one another and then try to schedule longer meeting times (sometimes every other week) so we could dive deeper into the material and have more time to focus on the task that week.

Comparatively, these examples suggest that having a rigorous structure in place to ensure that regular collaboration is happening and that progress is being made is essential to working positively in partnership in a program like the CDDCP, where students and instructors are expected to complete many self-directed tasks over a short period of time.

The factors discussed in this section provide us with valuable insight moving forward with the CDDCP. Firstly, though the CDDCP has a rigorous program structure relative to other Students-as-Partner programs (Healey et al., 2016; Jensen \& Bagnall, 2015), our findings provide a convincing argument that it should be maintained as it has demonstrably increased partner accountability. Another advantage of scheduled meetings between participants is that they help foster a sense of community. As students have found this very valuable, the authors intend to offer more community-building opportunities to instructor partners in future offerings of the CDDCP. The completion of this study has also confirmed that pairing students and instructors from similar academic backgrounds is generally preferable in a partnership that is focused on course design. Although these findings contrast other findings that studentinstructor partnerships work best when the student is not a disciplinary expert (Cook-Sather, 2016), CDDCP coordinator observations, along with partner feedback, have confirmed that partners are more comfortable engaging in a project with a partner when they can be confident in their partner's knowledge and/or past experiences.

\section{CONCLUSION}

The CDDCP program, which was established to promote the student voice in course design and course delivery at McMaster University, puts into practice Healey et al.'s (2014) values underpinning partnership practice. However, analysis of student, instructor, and coordinator data revealed two significant additional factors for positive partnership work: partner experience and program structure. Each of the three roles (students, instructors, and coordinators) noted that their participation in the program was enhanced by their prior and program experience. Student partners find that their experience as learners and skills gained through participation in CDDCP events led to their success in making meaningful contributions to the course design/delivery process. Instructor partners found that prior experience working 
with students and engaging in scholarly teaching practices increased their willingness to share the process of course design/delivery with a student. Instructor partners also gained useful experiences by collaborating on course design/delivery and learning more about pedagogy through discussion with their student partners. Coordinators found their previous experiences working with students and faculty and in administrative roles to be useful. Although it has been shown to be a source of challenge, program structure was essential for bringing student and instructor partners together. As a result of the time commitment required to effectively participate in a rigorously structured student-instructor partnership program, student and instructor partners achieve more during their CDDCP experiences when measures are put in place to ensure that partner accountability and collaboration is built into the experience.

Institutional ethics approval for the use of secondary data was obtained.

\section{ACKNOWLEDGEMENTS}

We would like to thank past CDDCP partners for providing the user feedback that was essential to the continual improvement of the program and the writing of this article.

\section{NOTES ON CONTRIBUTORS}

Gabrielle Foran was a PhD student in physical chemistry at McMaster University and a CDDCP co-coordinator during the completion of this work. Gabrielle is currently a post-doctoral researcher at Université de Montréal.

Kris Knorr is the area lead for faculty development at the Paul R. MacPherson Institute for Leadership, Innovation, and Excellence in Teaching at McMaster University, Hamilton, Canada. Kris's research interests have involved investigating the professional development needs of faculty/instructors, identity as scholarship-of-teaching-and-learning (SoTL) researchers, and student partnerships in post-secondary education.

Rebecca Taylor is an educational developer with the Paul R. MacPherson Institute for Leadership, Innovation, and Excellence in Teaching at McMaster University. In her role, Rebecca delivers various faculty development programs and services, which includes co-coordinating the CDDCP.

\section{REFERENCES}

Chang, H., Longman, K. A., \& Franco, M. A. (2014). Leadership development through mentoring in higher education: A collaborative autoethnography of leaders of color. Mentoring \& Tutoring: Partnership in Learning, 22(4), 373-389. https://doi.org/10.1080/13611267.2014.945734

Clancy, T., Ferreira, C., \& Thompson, P. (2019). Student-faculty partnership as a foundation for authentic learning. Papers on Postsecondary Learning and Teaching: Proceedings of the University of Calgary Conference on Learning and Teaching, 3, 144-149.

Foran, G., Knorr, K. \& Taylor, R. L. (2020). Evaluating factors contributing to positive partnership 
Cook-Sather, A. (2010). Students as learners and teachers: Taking responsibility, transforming education, and redefining accountability. Curriculum Inquiry, 40(4), 555-575. Retrieved from https://www.jstor.org/stable/40962986

Cook-Sather, A. (2014). Student-faculty partnership in explorations of pedagogical practice: A threshold concept in academic development. International Journal for Academic Development, 19(3), 186-198. https://doi.org/10.1080/1360144X.2013.805694

Cook-Sather, A. (2015). Introduction: Extended student-faculty partnerships: Deepening insights, transforming relationships. Teaching and Learning Together in Higher Education, 15, 1-6. Retrieved from https://repository.brynmawr.edu/tlthe/vol1/iss15/

Cook-Sather, A. (2016). Undergraduate students as partners in new faculty orientation and academic development. International Journal for Academic Development, 21(2), 151162. https://doi.org/10.1080/1360144X.2016.1156543

Creswell, J. W. (2012). Educational research: Planning, conducting, and evaluating quantitative and qualitative research (3rd ed.). Upper Saddle Creek, NJ: Pearson Education.

Flint, A., \& Millard, L. (2018). "Interactions with purpose": Exploring staff understandings of student engagement in a university with an ethos of staff-student partnership. International Journal of Students as Partners, 2(2), 21-38. https://doi.org/10.15173/ijsap.v2i2.3410

Goff, L., \& Knorr, K. (2018). Three heads are better than one: Students, faculty, and educational developers as co-developers of science curriculum. International Journal for Students as Partners, 2(1), 112-120. https://doi.org/10.15173/ijsap.v2i1.3333

Healey, M., Flint, A., \& Harrington, K. (2014). Engagement through partnership: Students as partners in learning and teaching in higher education. The Higher Education Academy. Retrieved from https://www.advance-he.ac.uk/knowledge-hub/engagement-throughpartnership-students-partners-learning-and-teaching-

higher\#: :text=to\%20Knowledge\%2OHub-

Engagement\%20through\%20partnership\%3A\%20students\%20as\%20partners\%20in,an d\%20teaching\%20in\%20higher\%20education\&text=identifies\%20tensions\%20and\%20c hallenges\%20to,addressing\%20challenges\%20and\%20future\%20work.

Healey, M., Flint, A., \& Harrington, K. (2016). Students as partners: Reflections on a conceptual model. Teaching \& Learning Inquiry, 4(2), 1-13. https://doi.org/10.20343/teachlearninqu.4.2.3

Jensen, K., \& Bagnall, D. (2015). Student teaching and learning consultants: Developing conversations about teaching and learning. Journal of Education and Innovation, Partnership and Change, 1(1), 167.

https://doi.org/10.21100/jeipc.v1i1.167

Marquis, E., Jayaratnam, A., Mishra, A., \& Rybkina, K. (2018). "I feel like some students are better connected than others": Students' perspectives on applying for extracurricular partnership opportunities. International Journal for Students as Partners, 2(1), 64-81. https://doi.org/10.15173/ijsap.v2i1.3300

Marquis, E., Puri, V., Wan, S., Ahmad, A., Goff, L., Knorr, K., Vassileva, I., \& Woo, J. (2016). Navigating the threshold of student-staff partnerships: A case study from an Ontario 
teaching and learning institute. International Journal for Academic Development, 21(1), 4-15. https://doi.org/10.1080/1360144x.2015.1113538

Martens, S. E., Sprujit, A., Wolfhagen, I. H. A. P., Whittingham, J. R. D., \& Dolmans, D. H. J. M. (2019). A student's take on student-staff partnerships: Experiences and preferences. Assessments \& Evaluation in Higher Education, 44(6), 910-919. https://doi.org/10.1080/02602938.2018.1546374

Matthews, K. E. (2017). Five propositions for genuine students as partners practice. International Journal for Students as Partners, 1(2), 1-9. https://doi.org/10.15173/ijsap.v1i2.3315

Mercer-Mapstone, L., Dvorakova, S. L., Matthews, K. E., Abbot, S., Cheng, B., Felten, P., Knorr, K., Marquis, E., Shammas, R., \& Swaim, K. (2017). A systematic literature review of students as partners in higher education. International Journal of Students as Partners, 1(1), 1-23. https://doi.org/10.15173/ijsap.v1i1.3119

Ntem, A., \& Cook-Sather, A. (2018). Resistances and resiliencies in student-faculty pedagogical partnership. International Journal for Students as Partners, 2(1), 82-96. https://doi.org/10.15173/ijsap.v2i1.3372

Oleson, K. C., \& Hovakimyan, K. (2017). Reflections on developing the student consultants for the teaching and learning program at Reed College, USA. International Journal for Students as Partners, 1(1), 1-8. https://doi.org/10.15173/ijsap.v1i1.3094

\section{APPENDIX I}

CDDCP End-of-Semester Reflection Questions (completed by student and instructor partners)

1. What were your primary goals for your partnership? To what degree were these goals achieved?

2. What did you learn about course design as a result of this partnership?

3. How did working in partnership influence the process of course design/delivery?

4. What were the primary challenges in working in partnership in course design/delivery? Were you able to overcome these challenges? If so, how? If not, what could the program do differently to support you?

5. What were the most beneficial aspects provided by the Course Design/Delivery Program Coordinators? What additional aspects would have benefited your partnership?

\section{APPENDIX II}

CDDCP Coordinator Focus Group Questions

1. How does the CDDCP differ from other programs that involve student-faculty partnership at McMaster University?

2. What are some of the inspirations behind the development and the implementation of the CDDCP?

3. What aspects of the CDDCP do you think are particularly effective? Why?

4. How would you define the coordinators' roles within the CDDCP? 
5. How have you contributed to the development and implementations of the CDDCP? What abilities and/or experiences have you brought to this program?

6. In what ways do you think that working with a student coordinator has influenced the delivery of the CDDCP?

7. What have you learned about students and/or faculty members through your role as a CDDCP coordinator?

8. In what ways do you think that student and/or faculty partners' perceptions of teaching and learning have changed as a result of their participation in the CDDCP?

9. What aspects of the CDDCP do you think are not working well, why?

10. What changes would you make to the CDDCP? Why? 